\title{
Posoqoypata, un cementerio Wari en el valle de Ayacucho, Perú
}

Posoqoypata, un cimetière Wari de la vallée d'Ayacucho, Pérou

Posoqoypata, a Wari Cemetery in the Ayacucho Valley, Peru

Lidio M. Valdez, J. Ernesto Valdez y Katrina J. Bettcher

\section{(2) OpenEdition}

\section{Journals}

\section{Edición electrónica}

URL: http://journals.openedition.org/bifea/7109

DOI: $10.4000 /$ bifea.7109

ISSN: 2076-5827

Editor

Institut Français d'Études Andines

Edición impresa

Fecha de publicación: 1 agosto 2001

Paginación: 335-357

ISSN: 0303-7495

\section{Referencia electrónica}

Lidio M. Valdez, J. Ernesto Valdez y Katrina J. Bettcher, « Posoqoypata, un cementerio Wari en el valle de Ayacucho, Perú », Bulletin de l'Institut français d'études andines [En línea], 30 (2) | 2001, Publicado el 08 agosto 2001, consultado el 07 diciembre 2020. URL : http://journals.openedition.org/bifea/7109 ; DOI : https://doi.org/10.4000/bifea.7109

\section{(c) $(1)$}

Les contenus du Bulletin de l'Institut français d'études andines sont mis à disposition selon les termes de la licence Creative Commons Attribution - Pas d'Utilisation Commerciale - Pas de Modification 4.0 International. 


\title{
POSOQOYPATA, UN CEMENTERIO WARI EN EL VALLE DE AYACUCHO, PERÚ
}

\author{
Lidio M. VALDEZ*, J. Ernesto VALDEZ ${ }^{* *}$ Katrina J. BETTCHER ${ }^{* * *}$
}

\begin{abstract}
Resumen
Recientemente efectuamos un trabajo de rescate arqueológico en un cementerio Wari en el valle de Ayacucho. Dicho trabajo permitió el descubrimiento de formas mortuarias totalmente novedosas para la región y para la cultura Wari en particular. La primera consiste en una cámara funeraria de forma rectangular, con un acceso orientado hacia el lado este, y que contenía los restos de varios individuos. La segunda tiene la forma de una pequeña cista de forma cilíndrica que contenía los restos de un individuo. En este ensayo describimos ambas formas mortuarias y comparamos con las estructuras mortuarias Wari excavadas a la fecha en el valle de Ayacucho. Por cuanto la primera forma mortuaria fue evidentemente accesible, también discutimos sus posibles implicancias en torno a la adoración del cuerpo de los ancestros. Esto considerando que un aspecto importante del ayllu de la época Inka fue la adoración del cuerpo de los ancestros, los mismos que eran guardados en estructuras mortuarias accesibles.
\end{abstract}

Palabras claves: Andes Centrales, Wari, cámara funeraria, cistas, ayllu.

\section{POSOQOYPATA, UN CIMETIÈRE WARI DE LA VALLÉE D’AYACUCHO, PÉROU}

\section{Résumé}

Nous avons récemment effectué un travail de sauvetage arquéologique dans un cimetière Wari de la vallée d'Ayacucho, ce qui a permis la mise à jour de deux formes mortuaires totalement nouvelles pour la région, et pour la culture Wari plus précisemment. La première consiste en une chambre funéraire de forme rectangulaire, avec un accès orienté à l'Est, et qui contenait les restes de plusieurs individus. La seconde est une petite sépulture en pierres de forme cylindrique qui contenait les restes d'un individu. Ce texte décrit les deux formes mortuaires et les compare avec les structures mortuaires Wari fouillées jusqu'à aujourd'hui dans la vallée d'Ayacucho. Étant

* Department of Anthropology, University of Alberta, Edmonton, Canadá. E-mails: lidio@ualberta.calvaldez@Peru.com

** Facultad de Ciencias Sociales, Universidad de Huamanga, Ayacucho, Perú. E-mail: warpa@Peru.com

*** Department of Anthropology, Trent University, Peterborough, Canadá. E-mail: kbettcher@trentu.ca 
donné qu'il est évident que la première forme mortuaire a été accessible, nous discutons ici les conséquences possibles pour l'adoration du corps des ancêtres, qui étaient conservés dans des structures mortuaires accessibles, cet élément étant considéré comme un aspect important de l'ayllu de l'époque Inka.

Mots clés : Andes centrales, Wari, chambre funéraire, sépulture en pierre, ayllu.

\title{
POSOQOYPATA, A WARI CEMETERY IN THE AYACUCHO VALLEY, PERU
}

\begin{abstract}
Recently we carried out an archaeological salvage excavation at a Wari cemetery in the Ayacucho Valley of central Peru. This intervention resulted in the discovery of two totally new mortuary structure forms for the region and the Wari culture in particular. The first form is a rectangular mortuary chamber, with a small east-facing entrance, where the remains of several individuals were found. The second form is a cylindrical cist built to contain the remains of one individual. In this essay we describe both mortuary forms and compare them to other known Wari mortuary structures of the region. Considering that the first form was evidently accessible, we also discuss the possible implications of this chamber with regards to ancestor worship, keeping in mind that an important aspect of ayllu organization during Inka times was the veneration of the ancestors' mummified bodies that were kept in accessible mortuary buildings.
\end{abstract}

Key words: Central Andes, Wari, Burial chamber, Cists, Ayllu.

\section{INTRODUCCIÓN}

"Era ver la gente que en este Cuzco había que ponía admiración [...] la más servía a estos muertos como tengo dicho, que cada día los sacaban a la plaza a todos, sentándolos en singlero cada uno con según su antiguedad, y allí comían y bebían los criados y criadas, y para los muertos hacíanles unas lumbres delante de ellos de una leña que tenían labrada y cortada muy igual y muy seca; encendida ésta quemaban aquí todo aquello que al muerto le habían puesto delante para que comiese de todo lo que ellos comían, y aquí en este fuego lo consumían. Tenían también delante destos muertos unos congilones grandes que ellos llamaban verquis de oro o de plata o de barro, cada uno como querían, y aquí echaban la chicha que al muerto le daban mostrándosela, convidándose unos muertos a otros, y los muertos a los vivos y los vivos a los muertos." (Pizarro, 1965: 192)

A su llegada al Cuzco en 1533, las huestes de Francisco Pizarro aprendieron que los cuerpos cuidadosamente momificados de los líderes antiguos eran guardados en el "palacio del muerto" bajo el vigilante cuidado de sus descendientes o ayllu. Asimismo, se supo que dichos cuerpos, vestidos con los tejidos más finos, eran periódicamente visitados, adorados, alimentados, y en ocasiones especiales incluso sacados a la plaza para ser consultados (ver Pizarro, 1965: 192; Rowe, 1946: 259; 1995: 30). Los cuerpos de otros ancestros también eran delicadamente envueltos en finos mantos y depositados en sepulcros especialmente construidos para dicha ocasión. En la versión del cronista Cieza de León (1973: 164), la forma de tales sepulcros variaba de una región a otra 
"porque en una parte las hacían hondas, y en otras altas, y en otras llanas, y cada nación buscaba nuevo género para hacer los sepulcros de sus difuntos."

Una característica sobresaliente de estos sepulcros es que eran accesibles. Tanto Cieza de León (1973: 165), como Bernabé Cobo (1956: 272), por ejemplo, señalan que dichos sepulcros estaban provistos de un pequeño acceso, generalmente con una orientación hacia el Este, y que estaba cubierto con una losa (ver Rowe, 1946: 286). Dicho acceso, o puerta, permitía "abrir las sepulturas y renovar la ropa y comida que en ellas habían puesto" (Cieza de León, 1973: 165). Puesto que en dichos sepulcros fueron depositados los cuerpos de varios individuos de diferentes edades, no cabe duda que el acceso también sirvió para depositar otros cuerpos, posiblemente miembros del mismo ayllu, en tiempos posteriores (ver Rowe, 1946: 286). Por último, un sepulcro dotado de un acceso, denota también el interés de los descendientes en mantener contacto con el ancestro, sea esto - como dice Cieza de León- para alimentar, renovar la ropa, depositar nuevas ofrendas, o consultarlo. Este fue el caso de las famosas chullpas que además de garantizar la preservación del cuerpo eran obviamente accesibles, permitiendo así la adición de nuevas ofrendas (Rowe, 1995: 29) y otros cuerpos, a la vez para facilitar la comunicación entre los ancestros y los vivos durante los actos rituales (ver Isbell, 1997: 138).

La organización del ayllu, y la veneración de los fundadores del ayllu, fue una de las características del estado Inka (Rowe, 1946: 253-255; Patterson, 1991: 65-67). El ayllu es un grupo de descendencia que identifica un ancestro común (ver Millones, 1981: 49; Moseley, 1992: 49). Pero, ¿cuándo surgió el ayllu por primera vez? ¿Fue el ayllu una organización establecida por el estado Inka? ¿o fue una organización que antecedió al estado Inka? ¿Por ejemplo, existió una organización similar en tiempos del desarrollo de la cultura Wari? Y sí, ¿cómo podemos los arqueólogos identificar la presencia del ayllu en tiempos pre-Inka? William Isbell sostiene que la "mejor manera de detectar el ayllu en el pasado es mediante la ubicación del cuerpo momificado de los ancestros y el sepulcro abierto" (Isbell, 1997: 139). El sepulcro abierto, siguiendo la definición de Isbell (1997:148), es una estructura construida sobre la superficie (como, o similar a, la chullpa), o una cueva, en la cual se podía ingresar sin dificultad alguna. Isbell (1997: 143-144) sostiene que al contrario del sepulcro abierto, existía el cementerio huaca donde el cuerpo era enterrado bajo tierra y "nunca" abierto. Sociedades asociadas con una huaca cementerio, en la opinión de Isbell, no estaban organizados mediante el sistema del ayllu.

Recientemente excavamos parcialmente un cementerio Wari en Posoqoypata, en el valle de Ayacucho, Perú (Fig. 1). La excavación (1) dejó en evidencia la presencia de varias cistas de forma cilíndrica, formas que no habían sido reportadas hasta la fecha para dicho valle. Asimismo, y ocupando un lugar central, se encontró una cámara funeraria de forma triangular y donde se hallaron los restos de entierros múltiples. El cementerio se ubica cerca de Seqllas, donde previamente excavamos otra cámara funeraria de características similares (Bettcher et al., 1999; Valdez et al., 2000). En este trabajo describimos los hallazgos del cementerio de Posoqoypata, dando énfasis a sus

(1) Este trabajo es producto de una intervención de emergencia, la misma que fue efectuada en coordinación con el Instituto Nacional de Cultura de Ayacucho. 


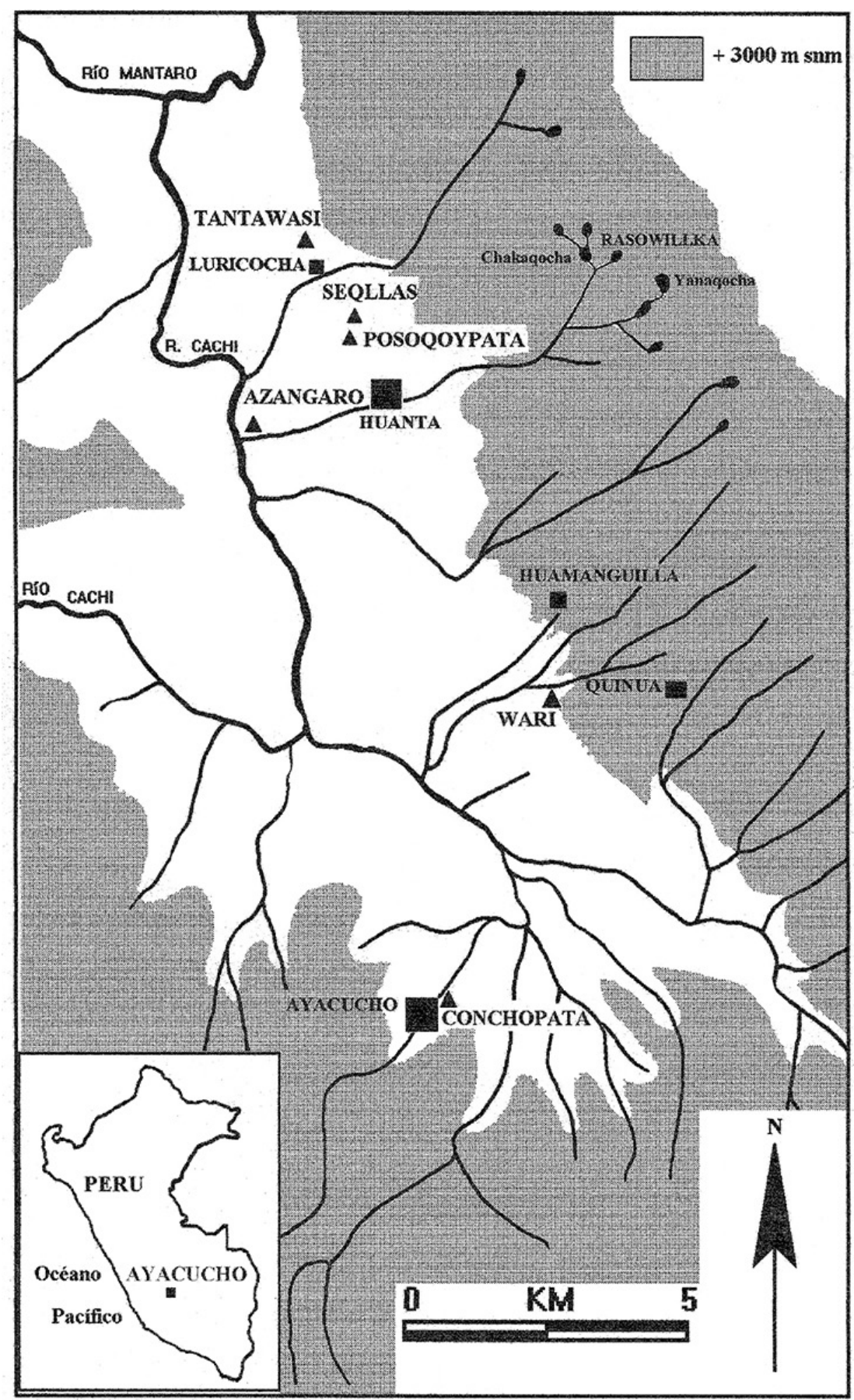

Fig. 1 - Ubicación del cementerio de Posoqoypata en relación a Seqllas y Wari en el valle de Ayacucho. 
formas constructivas y a su contexto. Teniendo como base esta nueva información, discutimos las implicancias de estas estructuras funerarias que son novedosas para el valle de Ayacucho y la cultura Wari.

\section{EL CEMENTERIO DE POSOQOYPATA}

Posoqoypata se encuentra aproximadamente a $15 \mathrm{Km}$ al norte del sitio arqueológico de Wari, y consiste en una pequeña colina ubicada a un margen de la carretera que une las ciudades de Huanta y Luricocha. Debido a los conflictos armados entre la guerrilla y el ejército peruano durante la década del ochenta, pobladores de las comunidades rurales ubicadas en la zona de puna optaron por abandonar sus lugares de origen y luego fueron reubicados en las inmediaciones de la ciudad de Huanta. Posoqoypata (conocido también como Chillicopampa) fue uno de estos lugares donde varias familias fueron reubicadas.

Al extremo norte de dicholugar, y justo al lado del coliseo deportivo, se encuentra el cementerio de Posoqoypata. El lugar también fue lotizado y posteriormente transferido a otro propietario, quien tiene previsto construir un "centro de educación". Como primer paso para dicha construcción, el 22 de julio de 2000, se empezó a bajar la elevación natural de la colina con un bulldozer. Fue en tales circunstancias que la máquina destapó 3 cistas (T1, T2 y T4) que fueron saqueadas justo después de su descubrimiento (2). A la llegada del segundo autor, ocurrida dos días más tarde, se encontraban abandonados varios fragmentos de huesos humanos en las inmediaciones de las cistas. Los vecinos y autoridades policiales de Huanta afirman que se logró extraer objetos de cerámica de las estructuras. De todos estos, sin embargo, sólo una vasija fragmentada fue posteriormente recuperada por la policía y nos fue entregada (ver adelante).

Puesto que el cementerio corría el peligro de ser destruido y desaparecer por completo, nosotros iniciamos el necesario trabajo de rescate arqueológico en coordinación con el Director del Instituto Nacional de Cultura de Ayacucho. La primera etapa del trabajo consistió en limpiar la superficie en un área de 11 x 7,5 m. para definir las estructuras ya expuestas y ubicar otras posibles aún no saqueadas. Durante este proceso se recuperaron fragmentos de cerámica, además de algunos huesos humanos. Una vez retirado el nivel superficial, se pudo observar la concentración de varias piedras semiplanas al lado noroeste de la excavación, mientras que otras pequeñas concentraciones de piedras aparecieron en otras partes. Dichos lugares fueron considerados como posibles lugares de enterramiento y posteriormente limpiados para definir nuestra suposición. El resultado de este rescate fue la ubicación de varias cistas similares a las expuestas por el bulldozer, además de una cámara funeraria de forma rectangular (ver Fig. 2).

(2) El segundo autor fue informado del hallazgo del cementerio varios días después del descubrimiento de las cistas. Para su llegada, T1 y T2 ya habían sido vandalizadas y los huesos humanos abandonados a la intemperie. 


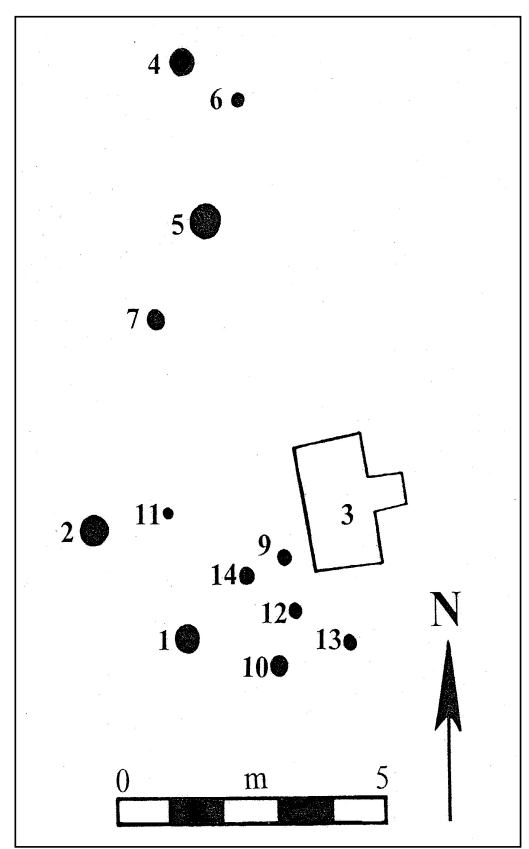

Fig. 2 - Ubicación de las cistas y la cámara funeraria de Posoqoypata.

\section{LAS CISTAS}

Un total de 12 cistas fueron descubiertas en Posoqoypata; fueron enumeradas en la medida de su descubrimiento (3). Excepto una (T5), todas presentan una estructura de piedra y barro, y por lo general son bien elaboradas. T5 consiste en una simple cista excavada sobre el suelo natural. No obstante las diferencias de tamaño, todas tienen de planta una forma circular y de corte una forma cilíndrica (ver Fig. 3, 4 \& 5). La base consistía en un piso elaborado en base a arcilla. En T4, sin embargo, una piedra plana con un orificio en su parte central había sido colocada precisamente en la base; sobre este hallamos huesos humanos bastante fragmentados pertenececientes a un individuo adulto y sus respectivas ofrendas.

Las cistas T6, T9, T11, T12, T13 y T14 son pequeñas. El diámetro de la apertura oscila entre 20 y $35 \mathrm{~cm}$., mientras que la profundidad no supera los $60 \mathrm{~cm}$. Sin embargo, todas presentan una pared construida en base a pequeñas piedras y barro. Estas cistas estaban bien selladas con una capa de arcilla, sobre la cual tal vez se había colocado una piedra. De la mayoría de estas cistas no recuperamos huesos identificables; por ejemplo, en T11 y T14 sólo encontramos huesos descompuestos. Una excepción fue T6 donde se encontró un fragmento de mandídula y varios dientes de niño, al lado de huesos muy descompuestos. También es importante resaltar que sólo en T11 se halló una ofrenda consistente en un silbato con figura antropomorfa. Considerando su tamaño pequeño,

(3) En nuestro registro no existe T8. Aquello que se excavó como tal resultó ser solamente una acumulación de piedras. 


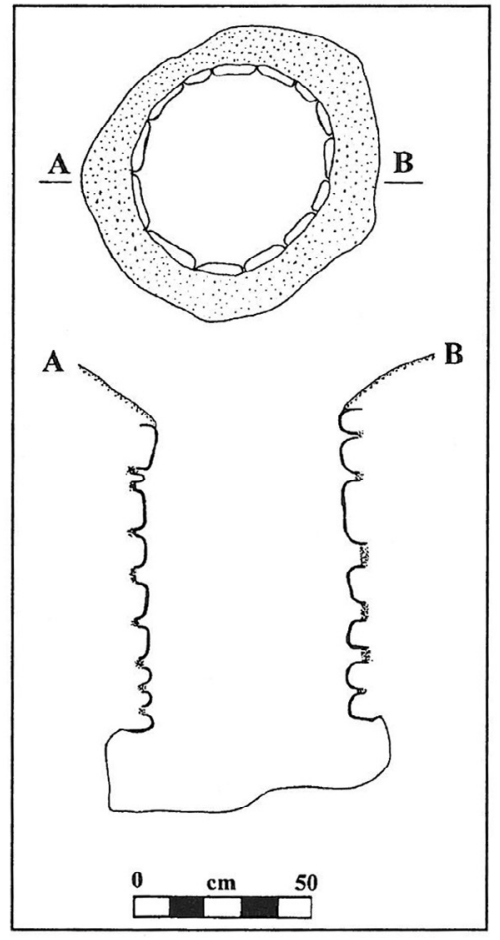

Fig. 3 - Detalle de la cista T1.

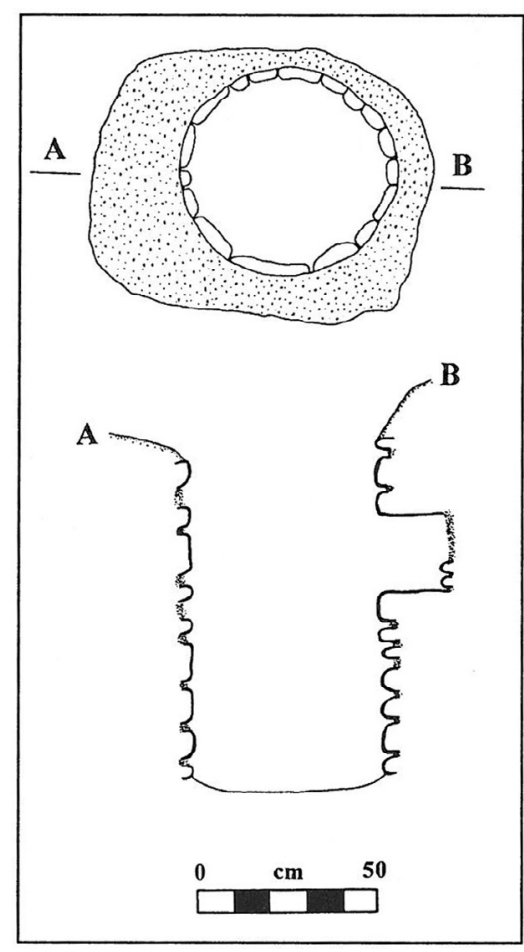

Fig. 4 - Detalle de la cista T2.

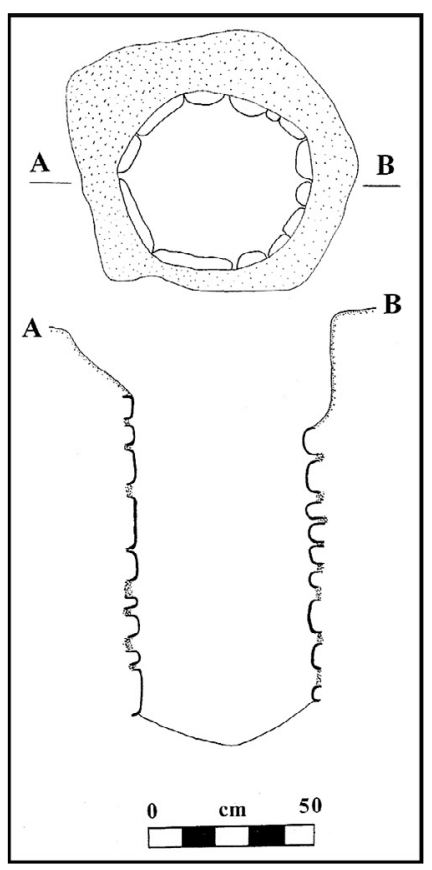

Fig. 5 - Detalle de la cista T4. 
la descomposición de los huesos y la presencia de dientes de niño en T6, las cistas pequeñas probablemente pertenecen a niños, además tal vez de algunos infantes. Es importante recordar que, debido a la preservación, los restos óseos de jóvenes y sobre todo de niños se limitan "en muchos casos sólo a los huesos más durables y los dientes" (Buikstra \& Ubelaker, 1994: 39).

Las cistas T1, T2, T4, T7 y T10 son un poco más grandes y profundas que las anteriores. Las estructuras también fueron construidas de piedra y barro, pero son mejor elaboradas que las anteriores. De todas estas, sólo T10 fue ubicada in situ (Fig. 6), y como tal, provee la necesaria información para definir, por ejemplo, la posición y orientación del individuo. T10 estaba cubierta con una piedra plana que servía de "techo". Una vez retirada dicha piedra se observó los huesos todavía articulados (excepto el cráneo, las costillas y los falanges) de un individuo que había sido colocado en una posición sentada, con las rodillas flexionadas hacia el pecho y con una orientación hacia el Este. Esta cista, a pesar de ser intacta, no poseía ofrenda alguna. La base era bastante compacta y seca, lo que permitió la relativa buena preservación de los huesos. La estructura tiene una abertura de $50 \mathrm{~cm}$. de $\mathrm{E}-\mathrm{O}$ x $45 \mathrm{~cm}$ de $\mathrm{N}-\mathrm{S}$, y una profundidad de $90 \mathrm{~cm}$. No obstante el buen estado de conservación de los huesos, muchos presentan fracturas, especialmente de las epífisis. Durante la recuperación, el largo máximo de los huesos más completos fue medido (4). La evaluación de los dientes de la mandíbula (Fig. 7) arroja una fórmula de 2I / 1C / 2P / 3M (5) característica de individuos adultos (ver Bass, 1987: 259-260). Además, el estado fusionado de las epífisis y el tamaño relativamente pequeño de los huesos largos (ver nota 5), sugieren que T10 contiene un individuo joven (¿adolescente?) de sexo indeterminado. Como se conoce, las epífisis se fusionan alrededor de los 14 y 16 años, dependiendo del sexo (ver Ubelaker, 1978: 63-69).

Las estructuras de T1, T2 y T4 son similares a la de T10. Al igual que esta última, dichas cistas también disponían de una cubierta que consistía en una piedra plana. Dichas piedras habían sido removidas por el bulldozer ocasionando su descubrimiento. La estructura de T7 también se parece a las arriba mencionadas, pero su forma es ligeramente globular y definitivamente es más profunda $(1,20 \mathrm{~m})$. Esta posiblemente también disponía de una cubierta, en la misma forma que T10. Como ya señalamos, T5 carece de la arquitectura elaborada de las otras cistas y, por lo tanto, es distinto.

A diferencia de las otras cistas, T2 presenta un pequeño nicho ubicado al lado Este (Fig. 4). De acuerdo con los testigos, una vasija decorada habría sido retirada de dicho nicho el día que esta cista fue destapada. Durante la limpieza que efectuamos encontramos una vasija zoomorfa que representa una alpaca (Fig. 8B), además de huesos humanos bastante fragmentados. Entre estos destaca una mandíbula, también fragmentada. De acuerdo con dicho elemento, el individuo había perdido todos los dientes molares, y las cavidades de erupción dentaria ya estaban del todo selladas.

(4) Las medidas obtenidas son: húmero $=26 \mathrm{~cm}$., femur $=34 \mathrm{~cm}$., cúbito $=20 \mathrm{~cm}$., peroné $=$ $28 \mathrm{~cm}$., tibia $=29 \mathrm{~cm}$.

(5) Esta fórmula (2I / 1C / 2P / 3M) se lee: 2 incisivos, 1 canino, 2 premolares, y 3 molares. Esto, multiplicado por 2 da como resultado 16 dientes, que es el total de dientes presentes en la mandíbula de un individuo adulto (mayor de 18 años). 


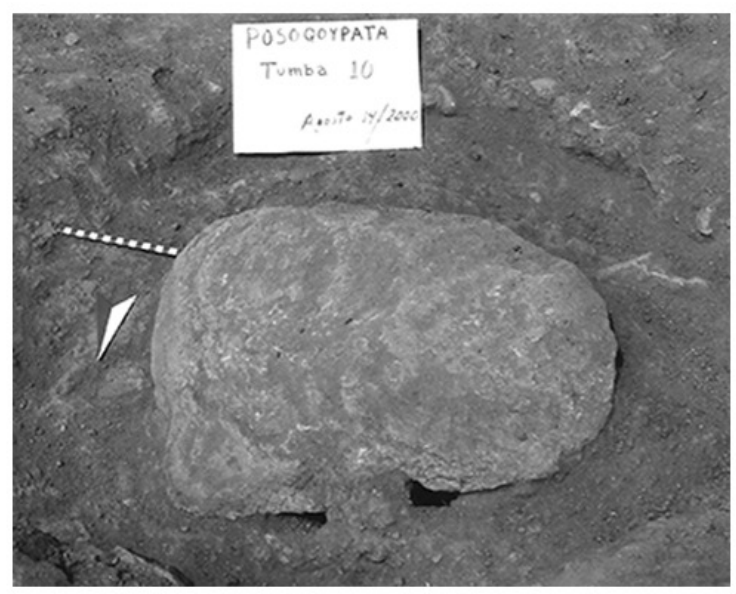

\section{A}

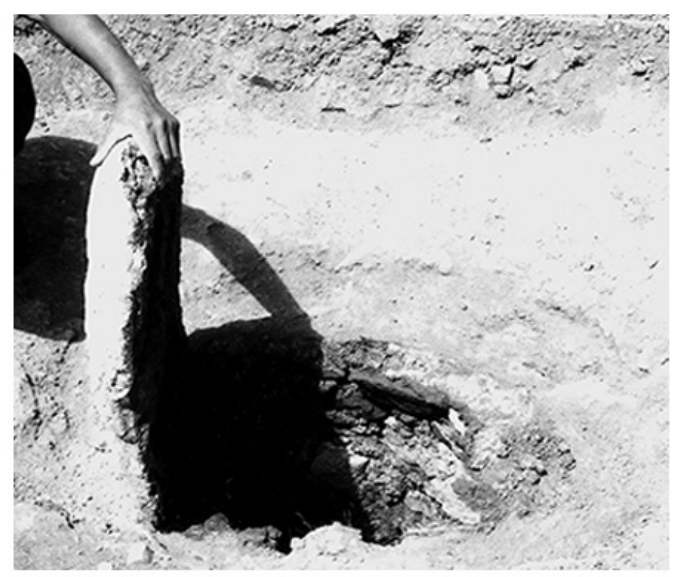

B
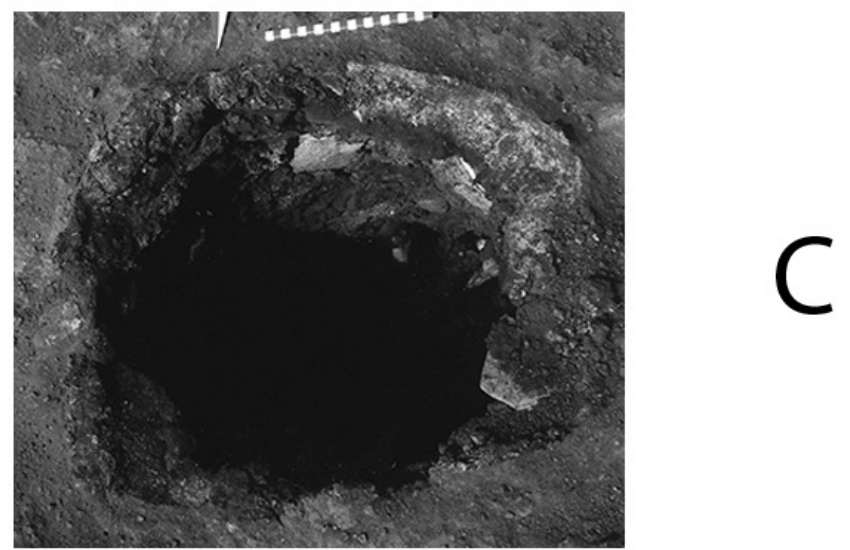

Fig. 6 - Detalle de T10: (A) antes de retirar la cubierta, (B) después de retirar la cubierta, y (C) detalle del interior de la cista. 


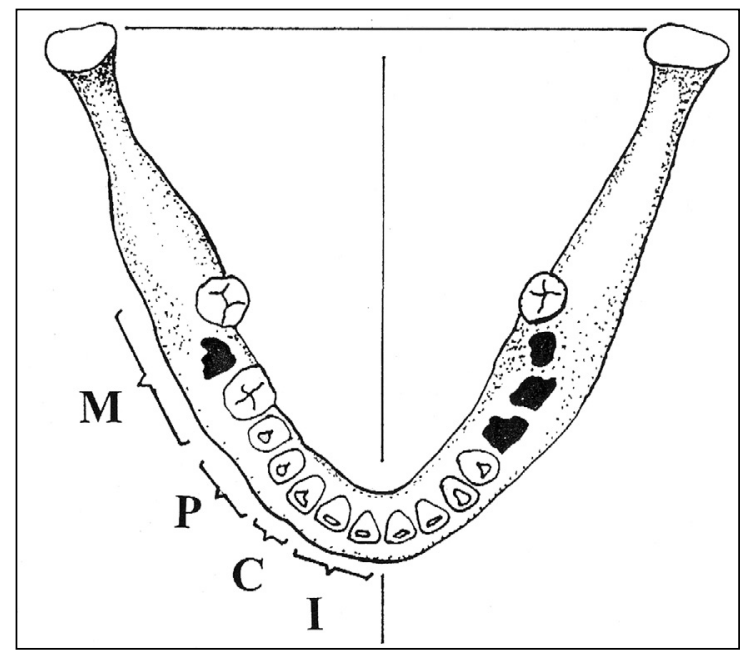

Fig. 7 - Mandíbula procedente de cista T10. Nótese la presencia de 3 molares, 2 premolares, 1 canino y 2 incisivos.

También se recuperaron otros huesos que presentan las epífisis ya fusionadas. Estas dos observaciones, aunque preliminares, sugieren que el individuo de T2 fue un adulto, tal vez de edad avanzada. En base a la forma de la cista, es posible que el individuo de T2 también haya mantenido una posición y orientación similares a la de T10. Esto quiere decir que el cuerpo estaba orientado hacia el nicho.

Entretanto, T1 presenta dos pequeños espacios vacíos a nivel del piso, que también tienen el aspecto de nichos (Fig. 3). Durante la limpieza efectuada después de su descubrimiento, se recuperó de esta cista solamente huesos deteriorados y bastante fragmentados que no permiten estimar la edad ni el sexo del individuo. Tampoco tenemos juicio alguno en relación a su orientación y posición, aunque dada su similaridad con T10, no es de dudar que este también estaba sentado con las rodillas flexionadas hacia el pecho.

T4 (Fig. 5) comparte muchas características con T1, T2 y T10. Por ejemplo, disponía también de una cubierta similar a la de T10. En comparación con T1 y T2, había sido parcialmente expuesta por el bulldozer, la misma que mayormente resultó en el rellenamiento de tierra [que provocó un relleno con tierra..?] al interior de la cista. Al igual que en los casos anteriores, los huesos recuperados de esta cista estaban bastante deteriorados y fragmentados. Entre estos huesos destaca la presencia de una mandíbula fragmentada. De acuerdo con este elemento, el individuo de T4 también había perdido todos los dientes molares, excepto uno y todos los premolares. Como resultado, las cavidades de erupción dentaria ya estaban completamente selladas, lo que sugiere que el individuo de T4 fue un adulto tal vez de edad avanzada, al igual que aquel de T2.

Así como notamos líneas arriba, y en contraste con las otras cistas hasta aquí mencionadas, durante la limpieza de T4 se recuperó un total de 4 vasijas. Esta colección incluye una pequeña vasija trípode, con asa cintada, de color negro y sin decoración (Fig. 8A). En su base presenta huellas de quema, lo que hace suponer que fue utilizada 


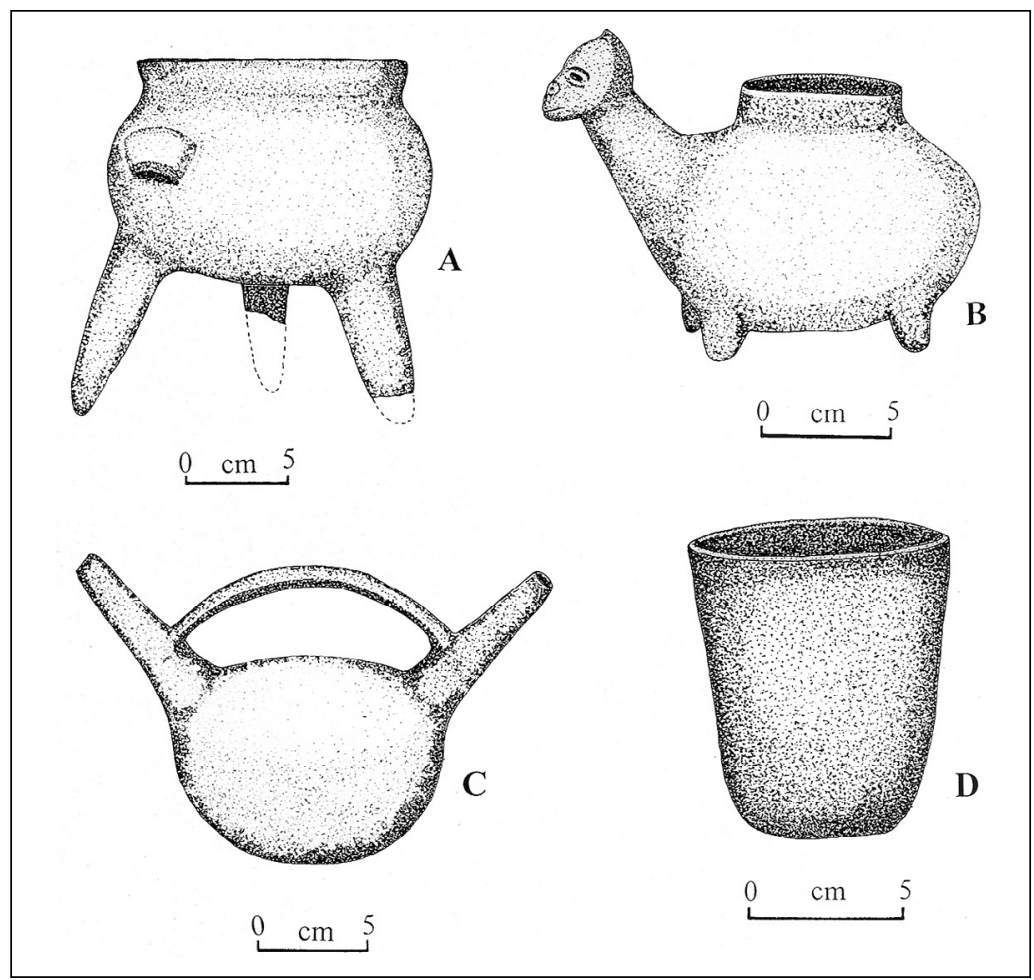

Fig. 8 - Cerámica de Posoqoypata: A y C T4, B T2 y D cámara .

para preparar algo, tal vez de función ritual. Se encontró también una vasija asa-puente, de color negro y sin decoración (Fig. 8C), así como una miniatura que representa una vasija abierta, provista de dos asas verticales y con decoración simple (Fig. 9B). Finalmente se halló la cabeza modelada de un puma, pintada de rojo oscuro y que presenta un orificio en su parte superior (Fig. 9A). Como hemos notado al inicio, en la base de esta cista encontramos una piedra plana con un orificio al centro. Dos piedras similares fueron halladas al interior de la cámara (ver adelante).

Finalmente, en T7 no encontramos huesos identificables como tampoco ofrenda alguna. Sin embargo, sí se logró recuperar dientes pertenecientes a individuos adultos. Esto sugiere que T7 también perteneció a un individuo adulto. El hecho de que esta cista sea más profunda que el resto de las estructuras hasta aquí referidas, sugiere también que ahí se depositó los restos de un individuo adulto.

En general, la mayor parte de las cistas de Posoqoypata parecen constituir entierros de individuos muy jóvenes que incluyen niños y posibles infantes. Junto a dichos entierros también habían algunas personas adultas (T1, T2, T4 y T7), pero cuyas edades exactas y sexo son difíciles de determinar debido al estado fragmentado y deteriorado de los huesos. De acuerdo con estos datos, se hace evidente que las cistas mejor elaboradas fueron construidas para los adultos, quienes a su vez parecen haber recibido un mayor número de ofrendas. De su lado, los adolescentes (T10), niños (T6) e infantes (T11) recibieron ofrendas sólo ocasionalmente. 


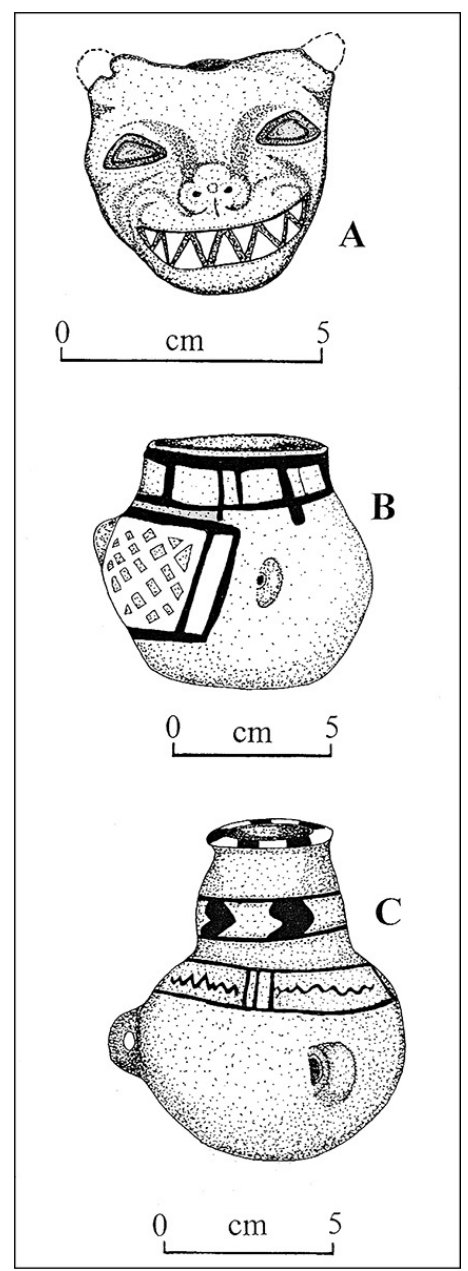

Fig. 9 - Cerámica de Posoqoypata: A y C T4, y B cámara.

Teniendo en cuenta la forma y el tamaño de las cistas, más la evidencia de T10, parece que la posición sentada, con las rodillas flexionadas hacia el pecho y tal vez con una orientación hacia el lado Este, fue un patrón común en Posoqoypata. De ser así, los individuos allí depositados habrían mantenido una orientación hacia la cámara funeraria (ver adelante). Vale la pena recordar que los entierros Nasca mantienen una posición idéntica a las de Posoqoypata (Carmichael, 1988: 182; 1995: 166). Esta posición, según John Rowe (1995: 28), correspondería a un individuo en descanso, pero que es asumido por los vivos como un individuo "despierto".

\section{LA CAMARA FUNERARIA DE POSOQOYPATA}

"La forma que le daban no era una sola en todo el reino, que como las provincias y naciones eran diversas, asi también diferentes maneras de sepulturas. Mas podemos reducir en dos géneros: el primero de lo que 
cavaban debajo de la tierra, y el segundo de los que levantaban encima de ella. De los primeros, unos eran muy hondas, a las cuales se bajaba por muchos escalones, y otros en un parejo en el suelo; los unos y los otros eran huecos como bóvedas, y tenían más o menos de labor y grandeza, según el estado de los que los hacían. Los más de estos tenían forma cuadrada, y algunos eran tan capaces y hondos como un ordinario aposento, con sus paredes de piedra tan bien labradas como los más primos edificios de los Inca. Dejábanles la puerta estrecha y cubierta con una losa, y algunos tenían debajo de la primera otra losa, y aun otras dos, muy juntos." (Cobo, 1956: 272)

La cámara, que se encuentra inmediatamente al lado de las cistas arriba referidas, había sido parcialmente expuesta por el bulldozer, y durante la excavación fue registrada como T3 (ver Fig. 2). No obstante estas limitaciones y su estado deteriorado, muchos de los aspectos observados en la cámara son comparables a la estructura funeraria de Seqllas ubicada a corta distancia al norte de Posoqoypata (ver Valdez et al., 2000). Por ejemplo, todo parece indicar que la cámara estaba sellada con una capa de arcilla, pero que gran porción había sido arrazada por el bulldozer. Dicha capa sellaba un conjunto de piedras planas, colocadas a manera de techo. Desafortunadamente, muchas de las piedras ya no mantenían su posición original, primero como resultado de la intervención del bulldozer y segundo, producto del saqueo que la cámara había sufrido, tal vez en tiempos antiguos (ver adelante). Merece recordar que la estructura de Seqllas tenía un techo construido con grandes lajas de piedra y sobre el cual se había colocado una capa de arcilla (Bettcher et al., 1999; Valdez et al., 2000).

Otro aspecto comparable entre ambas cámaras funerarias es su forma. Al igual que la estructura de Seqllas, la cámara recientemente ubicada en Posoqoypata también tiene una forma rectangular y sus paredes fueron construidas de piedra y barro (Fig. 10). Su largo (N a S), ancho (E a O) y profundidad, son 2,20 m., 1,20 m., 1,15 m., respectivamente. Su base era compacta, hecha de arcilla, sobre la cual se ubicaron dos grandes lajas de piedra con un orificio en la parte central. Una de las lajas mantenía todavía su posición original, y estaba bien sellada en el extremo suroeste de la cámara; una vez retirada esta piedra, se notó un pequeño espacio vacío, cuya función u objetivo desconocemos. Como hemos notado, en la base de T4 encontramos una laja similar.

Definitivamente, el detalle más sobresaliente de la estructura de Posoqoypata es su acceso que estaba ubicado al lado Este. La base del referido acceso se encuentra a una elevación mayor que la misma base de la cámara, y estaba pavimentada con lajas de piedra. Sus paredes, que mantienen una ligera prolongación hacia el exterior (a modo de un canal), también estaban bien construidas, y la parte exterior estaba sellada con una piedra plana (ver Fig. 10). Este es otro aspecto comparable con la cámara funeraria de Seqllas, por cuanto esta última también disponía de un acceso, aunque relativamente más pequeño que el anterior (ver Bettcher et al., 1999; Valdez et al., 2000).

En conjunto, puede haber poca duda que ambas estructuras funerarias fueron accesibles. Como se ha notado líneas arriba, Cieza de León (1973: 165) y Cobo (1956: 272) dan referencia del acceso de los sepulcros, que estaba tapado con una losa por el lado exterior. El acceso, de acuerdo a la información de los cronistas, habría permitido 


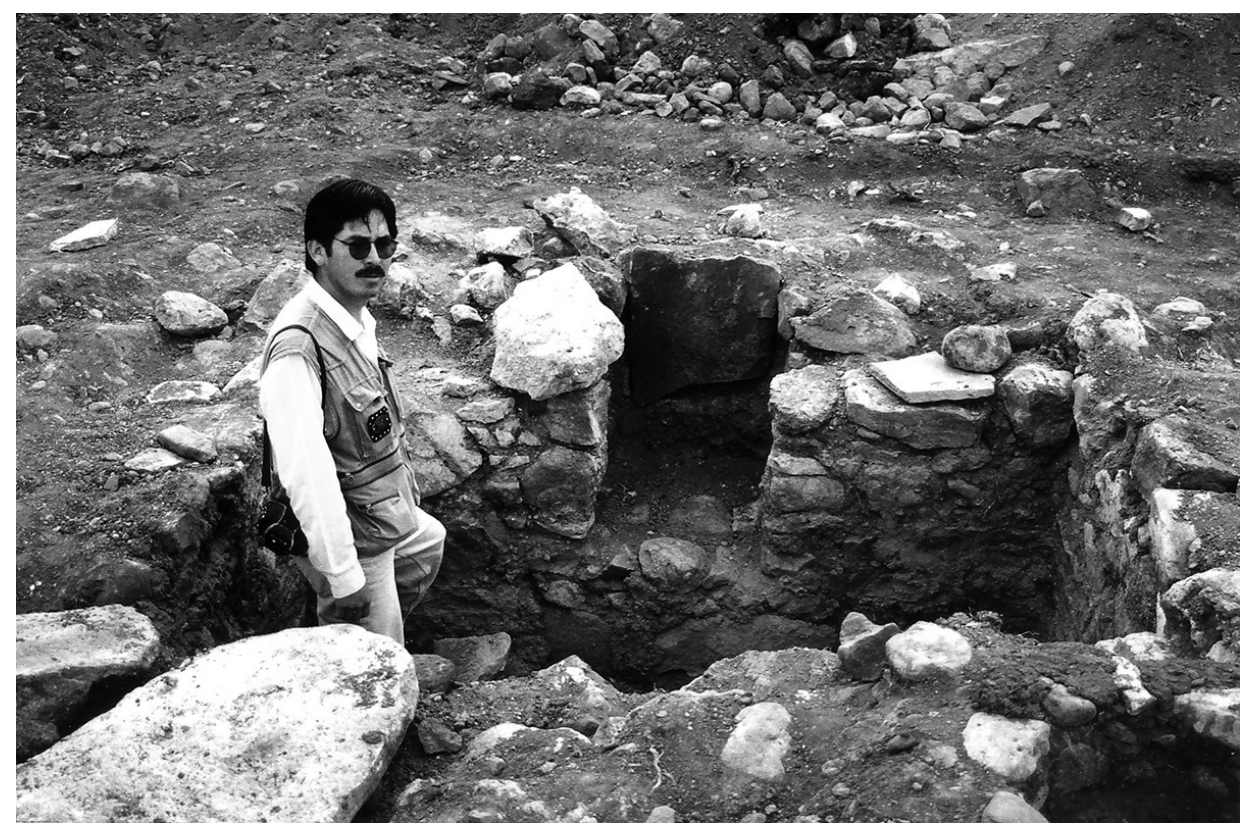

Fig. 10 - La cámara funeraria de Posoqoypata visto del lado oeste. Nótese el acceso y la piedra que sirvió para tapar.

renovar el vestido y las ofrendas de los muertos, además de colocar otros cuerpos. Por lo tanto, la evidencia proveniente de Posoqoypata y Seqllas sugiere que el cuidado y veneración hacia los muertos, similar a lo practicado durante la época Inka, ya se hacía en el valle de Ayacucho durante el Horizonte Medio.

Aunque es difícil conocer la cantidad exacta de individuos depositados en la cámara de Posoqoypata, es importante resaltar que su tamaño es más grande que la estructura funeraria de Seqllas. Esta diferencia tal vez indica que un número mayor de individuos fueron depositados allí. Como se sabe, en Seqllas se habían depositado los cuerpos de un mínimo de 14 individuos de varias edades (incluyendo a los niños) y probablemente de ambos sexos (Valdez et al., 2000). Los huesos hallados al interior de la cámara de Posoqoypata, comprendiendo los huesos del cráneo de por lo menos 4 personas, generalmente pertenecen a individuos adultos. Sin embargo, junto a dichos huesos también recuperamos los de un infante (sin el cráneo) y otros que pertenecen a niños. En consecuencia, esta evidencia es comparable a la proveniente de Seqllas, y todo parece indicar que en la cámara de Posoqoypata fueron depositados los cuerpos de varios individuos de diferentes edades y posiblemente de ambos sexos. Estos cuerpos, tal vez relacionados (ayllu), posiblemente fueron depositados a lo largo de varios años.

Parece evidente que la estructura funeraria fue construida con cuidado, y posiblemente bien elaborada. El objetivo debió haber sido preservar unidos los cuerpos de los individuos fallecidos al interior de una estructura bien hecha, segura, y sobre todo accesible. Su ubicación, en una colina lo suficientemente elevada, posiblemente fue también estratégica para evitar, por ejemplo, inundaciones que podrían haber ocasionado 
el rápido deterioro de los restos allí depositados. Al mismo tiempo, dicha ubicación debió haber resaltado su importancia, aunque la cámara en sí tal vez no fue visible a la distancia debido a su ubicación subterránea.

Los cuerpos depositados al interior de la cámara posiblemente estaban acompañados de un ajuar funerario numeroso y variado, depositado a lo largo de varios años. La presencia de este ajuar parece haber sido una de las razones que llevó a la inicial destrucción de la estructura funeraria; efectivamente, el muro del lado noroeste había sido parcialmente destruido, ocasionando el parcial derrumbamiento del techo y el probable saqueo del ajuar funerario. Dado que dicha intervención no se hizo por el acceso de la cámara, queda evidente que para dicha fecha la estructura ya estaba totalmente sellada, fuera de uso, y el acceso posiblemente clausurado. Esta intervención bien pudo haberse dado en tiempos prehispánicos, o durante el proceso de la extirpación de idolatrías (ver Rowe, 1995: 35). No obstante dicho saqueo, varios fragmentos de cerámica decorada y algunas vasijas fragmentadas habían sido abandonadas dispersas al interior de la misma cámara. Estas, sin lugar a dudas, son de mucha importancia para poder determinar la cronología relativa de dicha estructura mortuaria.

Todos los fragmentos de cerámica decorada encontrados al interior de la cámara son identificables como Wamanga (Viñaque Secular) y Viñaque, ambos pertenecientes a la época 2 del Horizonte Medio (Menzel, 1964; Lumbreras, 1974a). Junto a dichos tiestos también se recuperó un vaso del estilo Wari Negro (Fig. 8D), perteneciente a la época 1B del Horizonte Medio. Otra ofrenda consiste en una miniatura que representa una cantimplora (Fig. 9C), provista de dos asas verticales y decorada con el estilo Wamanga. Merece recordar que las muestras de cerámica recuperadas de T4 también pertenecen a la época 2 del Horizonte Medio. De este modo, todo parece indicar que la cámara de Posoqoypata, y el cementerio en general, fueron construidos y utilizados desde la época 1B del Horizonte Medio y continuados hasta la época 2.

Para el caso de Seqllas también se recuperó cerámica del Horizonte Medio época $1 B$ y época 2, además de la boquilla de una ocarina y un posible fragmento Warpa Negro/ Blanco. Puesto que las ocarinas son características de la cultura Warpa perteneciente al Periodo Intermedio Temprano (ver Lumbreras, 1974a: 136), se sugerió que la cámara funeraria de Seqllas tal vez fue inicialmente construida durante dicho periodo y utilizada hasta la época 2 del Horizonte Medio(Valdez et al., 2000). Luis Lumbreras (comunicación personal, 2000) señala que las ocarinas, si bien inicialmente manufacturadas durante el desarrollo de la cultura Warpa, continuaron siendo hechas durante el Horizonte Medio. Una evaluación más detallada del posible fragmento Warpa Negro/Blanco deja manifiesto que aquel no es Warpa, sino posiblemente parte de una olla utilitaria perteneciente al Horizonte Medio. Por lo tanto, la cerámica encontrada al interior de ambas estructuras funerarias indica que estas fueron construidas y utilizadas durante el Horizonte Medio.

En general, junto con lacámara de Seqllas, la evidencia proveniente de Posoqoypata es una segunda instancia donde se observan algunos aspectos del asíllamado "sepulcro abierto" por Isbell (1997: 156). Por ejemplo, Posoqoypata y Seqllas están aislados de otros sitios habitacionales contemporáneos. Para citar un ejemplo, Tantawasi se encuentra aproximadamente a $2 \mathrm{kms}$. al norte de Seqllas (ver Fig. 1). Además, ambas cámaras son relativamente pequeñas y presentan un techo bajo construido en base a 
grandes lajas de piedra. Finalmente, corroborando las observaciones tanto de Cieza de León (1973: 165) como de Cobo (1956: 272) acerca de las construcciones mortuarias, las cámaras de Posoqoypata y Seqllas presentan un acceso que mantiene una orientación hacia el lado Este. Vale la pena insistir en que las montañas del Rasowillka, consideradas como el principal wamani (montaña sagrada) del valle de Ayacucho, se encuentran precisamente del lado Este. No obstante la presencia de estos aspectos característicos de un "sepulcro abierto", las cámaras de Posoqoypata y Seqllas no son estructuras elevadas. Este aspecto y las posibles implicancias de estas estructuras en relación a la adoración de los ancestros (ayllu) son discutidos a continuación.

\section{DISCUSIÓN}

Isbell (1997) plantea, por un lado, que las sociedades andinas que estaban organizadas mediante el sistema del ayllu giraron en torno a la adoración de los cuerpos momificados de los ancestros que fueron cuidados y mantenidos en construcciones monumentales, identificables como el "sepulcro abierto". Por otro lado, las sociedades que enterraron sus muertos bajo tierra son identificadas como careciendo de una organización basada bajo el concepto del ayllu. En el modelo desarrollado por Isbell (1997: 287), el "sepulcro abierto" (y por ende, la adoración del cuerpo de los ancestros) habría hecho su aparición en la sierra norte (Cajamarca) durante el periodo Intermedio Temprano y luego difundido hacia el sur, llegando al valle de Ayacucho alrededor del Horizonte Medio, época 1B o época 2 (ver Isbell, 1997: 187-188). Como tal, la organización del ayllu no habría sido una institución que haya antecedido al estado Wari; más bien, su aparición habría contribuido a la caida de dicho estado (Isbell 1997: 298).

En la opinión de Isbell (1997), la presencia del "sepulcro abierto" y el cuerpo de los ancestros serían indicadores de la existencia de una organización social arqueológicamente identificable como ayllu. Además, Isbell (1997: 29) propone que "la historia del ayllu es la historia del cuerpo momificado de los ancestros y esta es la historia de las chullpas y formas mortuarias similares donde los cuerpos de los ancestros podrían ser cuidados". Este planteamiento deja implícito, primero, que una estructura mortuaria es indispensable para la existencia del ancestro. Segundo, dicha propuesta implica continuidad histórica en tanto que asume que las sociedades son inmutables (ver Browman, 1998; Bawden, 2000). Esta posición es evidente cuando Isbell (1997: 139) sugiere que "la mejor manera de detectar el ayllu en el pasado es mediante la ubicación del cuerpo de los ancestros y su sepulcro abierto", el mismo que como ya se señaló habría hecho su aparición en la sierra norte durante el periodo Intermedio Temprano. Esto sugiere que a lo largo de su historia el comportamiento del ayllu con respecto a la adoración de los muertos fue inmutable.

Tal como señala Bawden (2000: 146), el razonamiento de Isbell es circular por cuanto una vez reconocido el "sepulcro abierto" como la singular estructura funeraria que denota el ayllu, uno está obligado a aceptar que dicha organización existió en cualquier lugar y región donde dicha estructura está presente. En otras palabras, esta ecuación (sepulcro abierto = ayllu) puede fácilmente llevar a "encontrar" el ayllu cada vez que se encuentre dicha estructura mortuaria, y no dar lugar a que estructuras 
similares hayan cumplido funciones distintas. Entretanto, en su ausencia, se podría fácilmente concluir en favor de la ausencia del ayllu. De este modo, de acuerdo a esta noción, no existe posibilidad alguna que el ayllu y las prácticas mortuarias (ver Cieza de León, 1973: 164) hayan tenido variaciones temporales y/o regionales. Y, mientras los arqueólogos no encontremos el distintivo y aparentemente "indispensable sepulcro abierto", la existencia del ayllu no será reconocida, no obstante que el ayllu y la adoración de los ancestros haya antecedido al "sepulcro abierto" y/o haya existido sin dicha estructura mortuaria (ver Browman, 1998: 188).

Isbell (1997:108-109, 132), sin embargo, reconoce que las culturas y sus instituciones (incluido el ayllu) cambian, y es crítico de aquellos que promueven la idea de estabilidad cultural (ver Isbell, 1997: 30). No obstante esto, Isbell presenta al "sepulcro abierto" como un medio que nunca cambió, y que como tal puede servir para trazar el origen del ayllu. Por cuanto las sociedades, antiguas o contemporáneas, y sus respectivas instituciones son dinámicas y están sujetas a cambios, ya sea como respuesta a factores internos o influencias externas (ver Trigger, 1984: 284-285; Browman, 1998: 187), asumir que una institución como el ayllu no haya sufrido modificaciones en el pasado puede fácilmente conducirnos a conclusiones apresuradas $\mathrm{y}$, como no, falsas. Dicho esto, es importante explorar otras manifestaciones arqueológicamente detectables del ayllu, y sólo en esa medida podremos reflexionar mejor acerca de la antiguedad e importancia de dicha organización que, sin lugar a dudas, fue de mucha importancia durante la época Inka.

Para ratificar las sugerencias de Isbell, en el valle de Ayacucho encontraríamos evidencias del "sepulcro abierto" fechadas del Horizonte Medio, época 1B o época 2. Pero, ¿dónde están dichos "sepulcros abiertos" Wari? Desafortunadamente, no se conoce una sola estructura mortuaria Wari proveniente del referido valle que pueda ser identificada como tal. Los entierros de Conchopata, tal como anota Isbell (1997: 187), no tienen las características de un "sepulcro abierto" (ver Lumbreras 1974b: 112-113, 172). Evidencias adicionales puestas a la luz durante los trabajos más recientes en el referido sitio tampoco son distintos de los previamente ubicados; una excepción vendría a ser el caso de una estructura funeraria recientemente excavada, perteneciente al Horizonte Medio 2, y que contenía los restos de varios individuos (Anita Cook, comunicación personal, 2000). Sin embargo, dicha estructura no era elevada, sino subterránea. Finalmente, las estructuras de Cheqo Wasi (Wari), identificadas como "cámaras funerarias" por Benavides Calle (1991), tampoco tienen el aspecto de una chullpa, y menos se sabe si dichas estructuras fueron accesibles o no. De este modo, en todo el valle de Ayacucho no existe un solo ejemplo de estructura funeraria que pueda ser reconocido como "sepulcro abierto".

En comparación con las estructuras mortuarias Wari descubiertas hasta hace poco en la región, las cámaras funerarias de Posoqoypata y Seqllas son definitivamente diferentes. Por ejemplo, estos son los únicos ejemplos donde se observa por primera vez la presencia de accesos, sugiriendo que dichas estructuras fueron accesibles. Sin embargo, estas estructuras no encuadran perfectamente dentro de la categoría del "sepulcro abierto" o entierro bajo tierra; más bien, dichas cámaras combinan elementos de ambas categorías. Si bien no fueron construidas a modo de una chullpa, ambas 
estructuras eran accesibles por medio de pequeñas puertas. La presencia de los restos de varios individuos de diferentes edades al interior de estas cámaras también deja evidente que durante aquel tiempo ya había el interés en mantener juntos los restos de los muertos en estructuras cuidadosamente construidas para tales propósitos (Bettcher et al., 1999; Valdez et al., 2000). Asimismo, estos cuerpos habían sido dotados de ofrendas. La accesibilidad de las estructuras también deja abierta la posibilidad de que los cuerpos allí depositados fueron venerados, alimentados, consultados y tal vez sus vestidos renovados como en la época Inka, pero para esto no tenemos evidencias concretas.

Si este comportamiento, es decir la presencia de estructuras funerarias accesibles, implica veneración a los muertos, y si la suma de estos atributos es sinónimo de una organización identificable como el ayllu, las evidencias provenientes de Posoqoypata y Seqllas estarían reforzando la inicial sugerencia de Isbell (1997: 188), quien infiere que el concepto del ayllu hizo su aparición en el valle de Ayacucho durante el Horizonte Medio. Sin embargo, vale la pena insistir que la cámara funeraria de Posoqoypata (igual que la cámara de Seqllas) no puede ser identificada como un "sepulcro abierto". Esta es una diferencia notable en relación a la propuesta de Isbell (1997: 138), quien precisamente sostiene que "sin el cuerpo del ancestro y su sepulcro abierto no habría ayllu". Dada esta diferencia, queda manifiesto que el "sepulcro abierto" no es un requisito indispensable para identificar el ayllu. Esto siempre y cuando la presencia de una estructura mortuaria accesible implica la existencia de la organización del ayllu.

Cabe agregar que en las cámaras de Seqllas y Posoqoypata posiblemente fue difícil mantener en buen estado los cuerpos de los ancestros por largo tiempo, en particular considerando que los cuerpos estaban bajo tierra. Desde luego, el piso del que estaban dotados (más la ubicación de las cámaras en colinas) probablemente restó el fácil y rápido deteriodo de los cuerpos allí depositados. No obstante esto, parece más probable que los huesos de los muertos, y no necesariamente las momias, fueron adorados en Posoqoypata y Seqllas. Si esta observación es correcta, la presencia del cuerpo momificado del ancestro tampoco parece ser indispensable para la existencia del ayllu. Esta es una segunda variación con respecto a la sugerencia de Isbell (1997). De haber sido este el caso, la mejor manera de detectar el ayllu en el pasado podría ser mediante la ubicación de estructuras funerarias accesibles, asociadas a restos humanos (huesos) y sus respectivas ofrendas. Esto, una vez más, si el comportamiento del ayllu de la época Inka es aplicable a tiempos pre-Inka, y si la adoración de los ancestros siempre fue asociada a una forma particular de estructura funeraria.

Al lado de la cámara funeraria de Posoqoypata hay también varias cistas bien elaboradas y que parecen estar relacionadas con la cámara. La presencia de cerámica contemporánea tanto en la cámara como en algunas de las cistas así lo sugiere. La proximidad de ambos, a su vez, indica que las cistas y la cámara funeraria parecen haber sido ritualmente asociadas (6). Desde luego, por su forma, tamaño y ubicación, la cámara tal vez fue el lugar de mayor privilegio, denotando quizás incluso estatus sociales diferentes. Esto considerando que los individuos tratados de manera diferente una vez muertos, posiblemente también fueron tratados de manera distinta mientras

(6) Debemos señalar que en las inmediaciones de la cámara funeraria de Seqllas también hay entierros aislados, pero que ningunos fueron excavados a la fecha. 
estaban vivos (ver Goldstein, 1981: 54; O’Shea, 1984: 36). En consecuencia, los individuos depositados en la cámara tal vez pertenecieron a una clase social superior a aquellos depositados en las cistas. De ser válida esta observación, la posición sentada de los individuos depositados en las cistas, además de su proximidad, tal vez implica que éstos fueron los guardianes de los cuerpos depositados al interior de la cámara.

Sin embargo, cabe anotar que no hay diferencias entre los individuos depositados en la cámara y las cistas, por lo menos en cuanto a edad se refiere. Esto aunque haya un mayor número de niños fuera de la cámara de Posoqoypata. Como hemos notado, en la cámara habían sido depositados los cuerpos de varios individuos y edades. Los individuos depositados en las cistas también varían en cuanto a edad se refiere. Asimismo, los individuos depositados en la cámara y aquellos depositados en las cistas, por lo menos los adultos, recibieron varias ofrendas (7). Dicho esto, la única diferencia observable — a la fecha- es el hecho de que en la cámara fueron depositados los cuerpos de varios individuos, mientras que en las cistas sólo colocaron uno. ¿Tendrá esto alguna connotación de género? ¿Será que individuos de un sexo fueron depositados en un tipo de estructura y aquellos del sexo opuesto en formas distintas? Desafortunamente, el estado deteriorado y fragmentado de los huesos no permite responder a estas interrogantes. Por lo tanto, la recuperación de entierros adicionales y mejor conservados en el lugar (tal vez al lado este de la cámara) es de mucha importancia para definir mejor este aspecto que puede ayudar a explicar la evidencia proneviente de Posoqoypata.

Mientras la cámara tiene un acceso definido, indicando que la estructura fue accesible, las cistas carecen de un distintivo similar. ¿Sugiere esto que las cistas nunca fueron abiertas y los cuerpos nunca más vistos después del entierro? Por cuanto las cistas están bajo tierra y no tienen un acceso definido, fácilmente se puede asumir que estas nunca fueron abiertas (ver Isbell, 1997: 144). Pero es importante resaltar que la cubierta mantenía la misma profundidad que el techo de la cámara y consistía apenas en una piedra plana, similar a la laja que cubría el acceso de la cámara. Esto da la posibilidad de que dichas estructuras tal vez también fueron accesibles, en la misma forma como lo fueron los entierros Nasca (ver Carmichael, 1988: 373-375; 1995: 177). Por ejemplo, una laja con un orificio al centro fue encontrada al interior de T4, y lajas similares fueron halladas al interior de la cámara. Si la función de estas lajas tuvo alguna relación con las actividades efectuadas después del entierro, es posible que las cistas no fueran del todo selladas. Por lo tanto, no se puede afirmar que dichas cistas nunca fueron abiertas al igual que la cámara, como tampoco se puede negar que los individuos allí depositados no recibieron ofrendas adicionales después de su entierro. Para confirmar esta observación, desde luego, es preciso encontrar datos adicionales que sugieran algo en dicha dirección.

Si la presencia de la cámara funeraria señalada es representativa de una organización social identificable como ayllu, es importante saber cuál es la implicancia de las cistas previamente referidas. Siguiendo el modelo de Isbell (1997: 144), entierros bajo tierra indicarían que la sociedad no estaba organizada bajo el concepto del ayllu. Pero, y como hemos dejado manifiesto, en Posoqoypata también existe una estructura mortuaria obviamente accesible que tal vez tiene relación con la adoración de los

(7) Desde luego, las ofrendas recuperadas del interior de la cámara probablemente están lejos de reflejar el ajuar funerario original. 
ancestros. La presencia asociada de estas dos formas mortuarias, por lo tanto, pone en duda la aplicabilidad de la propuesta de Isbell. En efecto, utilizando la cámara funeraria se podría afirmar, y concluir, que el ayllu ya existió en el valle de Ayacucho durante el Horizonte Medio; entretanto, la sola y aislada presencia de las cistas llevaría a sostener que aquella organización no existió. Dicho esto, hay una mayor posibilidad que existieron variaciones de orden temporal, regional y cultural en cuanto al tratamiento de los muertos se refiere, variación ésta que bien pudo haber incluido al ayllu.

\section{CONCLUSIÓN}

Las estructuras mortuarias observadas en Posoqoypata (y Seqllas) son definitivamente diferentes de otras formas mortuarias Wari conocidas para el valle de Ayacucho. Esta diferencia parece tener una connotación cronológica. En efecto, en Conchopata (Horizonte Medio 1) los entierros fueron depositados en cistas simples, mientras que en Posoqoypata (Horizonte Medio 2) los cuerpos fueron colocados en estructuras bien elaboradas. De todas estas, una era evidentemente accesible. Al mismo tiempo, la posición de los entierros de Conchopata, por ejemplo, son de cúbito dorsal, mientras que los de Posoqoypata son flexionados. Finalmente, en Posoqoypata (y Seqllas) los entierros no estaban asociados a estructuras residenciales o públicas, y este es otro aspecto diferente del caso de Conchopata. En conjunto, éstos son cambios significativos e indican un comportamiento diferente de la sociedad hacia los muertos.

Puesto que las costumbres mortuarias son idiosincráticas, diagnósticas y sobre todo una institución muy conservadora dentro de una sociedad (P. Carmichael, comunicación personal 1998; Silverman, 1996: 5), la evidencia proveniente de Posoqoypata ya indica profundos cambios en cuanto al tratamiento de los muertos durante el Horizonte Medio en el valle de Ayacucho. En particular, la presencia de una estructura accesible, que es comparable con las estructuras mortuarias de la época Inka descritas por los cronistas, es novedosa para el caso Wari. Si la presencia de aquella estructura (y la de Seqllas) implica la adoración de los ancestros, similar a aquella de la época Inka, y si este comportamiento también denota la presencia de una organización identificable como el ayllu, parece probable que aquella organización ya existió en el valle de Ayacucho durante el periodo del desarrollo de la cultura Wari. Sin embargo, aquella ecuación puede conducir a conclusiones apresuradas y tal vez erróneas, especialmente considerando la enorme variación regional de las culturas del antiguo Perú. Por lo tanto, hasta que se obtengan datos adicionales en favor de esta interpretación, la evidencia aquí presentada no puede ser interpretada como una expresión inquestionable del ayllu.

Junto a la cámara funeraria están presentes cistas bien elaboradas que también son formas novedosas para el valle de Ayacucho. Dado que ambas formas mortuarias son nuevas para la región, un posible escenario es que ambas tengan un origen en algún lugar fuera del valle de Ayacucho. Por ejemplo, la posición de los individuos de las cistas guarda mucha afinidad con los entierros Nasca. Considerando que los habitantes de la costa sur y el valle de Ayacucho mantuvieron permanente contacto (Menzel, 1964), es posible que aquella forma mortuaria sea el resultado de dicha interacción. No obstante 
esta posibilidad, no se puede descartar que ambas formas mortuarias son innovaciones locales y que respondieron a fenómenos sociales locales que por ahora desconocemos.

Lo observable es que durante el Horizonte Medio 2 no había una sola forma de estructura funeraria en el valle de Ayacucho. Definitivamente, algunos cuerpos estaban enterrados juntos en estructuras amplias y accesibles, mientras que otros colocados separados y en estructuras más pequeñas. Si esta diferencia implica una estratificación social, una diferenciación en cuanto a género, o la presencia de grupos étnicos distintos, queda por resolverse. En la medida del avance de los trabajos arqueológicos en la región, es posible que formas mortuarias adicionales sean identificadas lo que ayudaría a reflexionar mejor acerca del significado de dichas variaciones y sus posibles implicancias con respecto a la adoración de los ancestros. Esto en particular considerando que las formas mortuarias Wari siguen siendo parcialmente desconocidas.

En síntesis, dos cámaras funerarias Wari que exiben razgos totalmente novedosos para el valle de Ayacucho han sido recientemente excavadas. Un aspecto sobresaliente de ambas estructuras es su accesibilidad, que una vez más tal vez tiene una asociación con el ayllu. De ser así, la presencia de estructuras funerarias accesibles, asociadas a huesos humanos y sus respectivas ofrendas podría ser una forma de detectar el ayllu en el pasado. Sin embargo, y por las razones discutidas en la sección anterior de este texto, dicha posibilidad se debe manejar con cuidado. Por lo tanto, el hallazgo de otras estructuras funerarias en la región es indispensable.

\section{Agradecimientos}

Nuestro reconocimiento a todas las personas que de una u otra forma participaron en los trabajos de rescate en el cementerio de Posoqoypata. La decisión tomada por el Director del Instituto Nacional de Cultura de Ayacucho, el antropólogo Mariano Benites, para llevar adelante este trabajo fue de particular importancia considerando que la información obtenida es totalmente novedosa. Sin aquella decisión, toda información acerca del cementerio de Posoqoypata fácilmente se hubiera destruido. Nuestros agradecimientos se extienden a las autoridades locales de Huanta y a la Policia Nacional de Huanta por el interés en los trabajos realizados en Posoqoypata. Finalmente, nuestras gracias para Helaine Silverman y John Topic por los comentarios y sugerencias a una versión inicial de este trabajo. Del contenido y las ideas presentadas en este trabajo, desde luego, nosotros somos los únicos responsables. 


\section{Referencias citadas}

BASS, W.M., 1987 - Human Osteology: a laboratory and field manual (3ra. edición), 327p.; Columbia: Missouri Archaeological Society.

BAWDEN, G., 2000 - Burial: the deus ex machina of social transformation? Current Anthropology, 41(1): 145-147.

BENAVIDES CALLE, M., 1991 - Cheqo Wasi, Huari. In: Huari Administrative Structure: Prehistoric Monumental Architecture and State Government (W.H. Isbell \& G.F. McEwan, eds.): 55-69; Washington, D.C.: Dumbarton Oaks.

BETTCHER, K.J., VALDEZ, J.E. \& VALDEZ, L. M., 1999 - Salvage excavation of a Wari burial chamber at Seqllas, Ayacucho Valley, Peru. Ponencia presentada al 18th Annual Northeast Conference on Andean Archaeology and Ethnohistory, University of Massachusetts, Amherst, Octubre 23 - 24, 1999.

BROWMAN, D. L., 1998 - Review of Isbell. Latin American Antiquity, 9(2): 186-188.

BUIKSTRA, J.E. \& UBELAKER, D.H., 1994 - Standards for Data Collection from Human Skeletal Remains, 202p.; Arkansas Archaeological Survey Research. Series No 44.

CARMICHAEL, P.H., 1988 - Nasca Mortuary Customs: death and ancient society on the South Coast of Peru, 587p.; Calgary: University of Calgary, Ph.D. Dissertation, Department of Archaeology,

CARMICHAEL, P.H., 1995 - Nasca burial patterns: social structure and mortuary ideology. In: Tombs for the Living: Andean Mortuary Practices (T. D. Dillehay, ed.): 161-187; Washington, D.C.: Dumbarton Oaks.

CIEZA DE LEÓN, P., 1973[1553] - La Crónica del Perú, 262p.; Lima: Ediciones Peisa.

COBO, B., 1956[1653] - Historia del Nuevo Mundo. In: Obras del Padre Bernabé Cobo, Segunda Parte: 5-275; Madrid: Ediciones Atlas. Biblioteca de Autores Españoles Tomo XCII.

GOLDSTEIN, L., 1981 - One-dimensional archaeology and multi-dimensional people: spatial organization and mortuary analysis. In: The Archaeology of Death (R. Chapman, I. Kinnes \& K. Randsborg, eds.): 53-69; Cambridge: Cambridge University Press.

ISBELL, W. H., 1997 - Mummies and Mortuary Monuments: a postprocessual prehistory of Central Andean organization, 357p.; Austin: University of Texas Press.

LUMBRERAS, L.G., 1974a - Las Fundaciones de Huamanga: hacia una prehistoria de Ayacucho, 238p.; Lima: Editorial Nueva Educación.

LUMBRERAS, L.G., 1974b - The Peoples and Cultures of Ancient Peru, 248p.; Washington, D.C: Smithsonian Institution Press.

MENZEL, D., 1964 - Style and time in Middle Horizon. Ñawpa Pacha, 2: 1-105; Berkeley.

MILLONES, L., 1981 - Introducción. In: Etnohistoria y Antropología Andina (A. Castelli, M. Koth de Paredes \& M. Mould de Pease, eds.): 49-53; Lima: Segunda Jornada del Museo Nacional de Historia.

MOSELEY, M. E., 1992 - The Incas and their Ancestors: The archaeology of Peru, 272p.; London: Thames \& Hudson.

O'SHEA, J. M., 1984 - Mortuary Variability: an archaeological investigation, 338 p.; New York: Academic Press.

PATTERSON, T.C., 1991 - The Inca Empire: the formation and disintegration of a pre-capitalist state, 211p.; New York: Berg Publishers, Inc.

PIZARRO, P., 1965[1571] - Relación del Descubrimiento y Conquista de los Reinos del Perú. In: Biblioteca de Autores Españoles Tomo CLXVIII: 159-242; Madrid: Ediciones Atlas.

ROWE, J. H., 1946 - The Inca culture at the time of the Spanisch Conquest. In: Hanbook of South American Indians: The Andean Civilizations, Vol. 2. (J. H. Steward, ed.): 183-330; Washington, D.C.: Smithnosian Institution. Bureau of American Ethnology Bulletin 143. 
ROWE, J. H., 1995 - Behavior and belief in ancient Peruvian mortuary practices. In: Tombs for the Living: Andean Mortuary Practices (T. D. Dillehay, ed.): 27-41; Washington, D.C.: Dumbarton Oaks.

SILVERMAN, H., 1996 - Contextualizando la muerte en los cementerios Paracas. In: Al Final del Camino (L. Millones \& M. Lemlij, eds.): 1-19; Lima: Seminario Interdisciplinario de Estudios Andinos.

TRIGGER, B. G., 1984 - Archaeology at the crossroads: what's new? Annual Review of Anthropology, 13: 275-300.

UBELAKER, D. H., 1978 - Human Skeletal Remains: Excavation, Analysis, Interpretation (Second edition), 172p.; Washington, D.C.: Taraxacum. Manuals in Archaeology 2.

VALDEZ, L.M., BETTCHER, K.J. \& VALDEZ, J. E., 2000 - Una Cámara Funeraria en Seqllas, Ayacucho. Boletín del Museo de Arqueología yAntropología,3(7): 2-7; Lima: Universidad Nacional Mayor de San Marcos. 